\title{
Identification of $q R B S 1$, a QTL involved in resistance to bacterial seedling rot in rice
}

\author{
R. Mizobuchi $\cdot$ H. Sato $\cdot$ S. Fukuoka $\cdot$ S. Tsushima $\cdot$ \\ T. Imbe $\cdot$ M. Yano
}

Received: 7 March 2013 / Accepted: 14 June 2013 / Published online: 25 June 2013

(C) The Author(s) 2013. This article is published with open access at Springerlink.com

\begin{abstract}
Bacterial seedling rot (BSR), a destructive disease of rice (Oryza sativa L.), is caused by the bacterial pathogen Burkholderia glumae. To identify QTLs for resistance to BSR, we conducted a QTL analysis using chromosome segment substitution lines (CSSLs) derived from a cross between Nona Bokra (resistant) and Koshihikari (susceptible). Comparison of the levels of BSR in the CSSLs and their recurrent parent, Koshihikari, revealed that a region on chromosome 10 was associated with resistance. Further genetic analyses using an $\mathrm{F}_{5}$ population derived from a cross between a resistant CSSL and Koshihikari confirmed that a QTL for BSR resistance was located on the short arm of chromosome 10. The Nona Bokra allele was associated with resistance to BSR. Substitution mapping in the Koshihikari genetic background demonstrated that the QTL, here designated as qRBS1 (quantitative trait locus for RESISTANCE TO BACTERIAL SEEDLING ROT 1), was located in a 393-kb interval (based on the
\end{abstract}

Communicated by T. H. Tai.

R. Mizobuchi $(\bowtie) \cdot$ S. Fukuoka $\cdot$ M. Yano

National Institute of Agrobiological Sciences, Kannondai 2-1-2, Tsukuba, Ibaraki 305-8602, Japan

e-mail: ritsuko@affrc.go.jp

H. Sato

National Agriculture and Food Research Organization (NARO), National Institute of Crop Science, Kannondai 2-1-18, Tsukuba, Ibaraki 305-8518, Japan

S. Tsushima

National Institute of Agro-Environmental Sciences, Kannondai 3-1-3, Ibaraki 305-8604, Japan

T. Imbe

National Agricultural and Food Research Organization,

3-1-1 Kannondai, Tsukuba, Ibaraki 305-8517, Japan
Nipponbare reference genome sequence) defined by simple sequence repeat markers RM24930 and RM24944.

\section{Introduction}

Burkholderia glumae causes bacterial seedling rot (BSR) and bacterial grain rot (bacterial panicle blight) in rice (Oryza sativa L.), which are increasingly important diseases in global rice production (Ham et al. 2011b). Since disease caused by B. glumae was first discovered in Japan (Goto and Ohata 1956; Goto et al. 1987; Kurita and Tabei 1967; Uematsu et al. 1976a), it has also been reported in other countries in East Asia (Azegami 2009; Chien and Chang 1987; Cottyn et al. 1996a; Cottyn et al. 1996b; Jeong et al. 2003; Luo et al. 2007; Trung et al. 1993) and Latin America (Nandakumar et al. 2007b; Zeigler and Alvarez 1989). In the USA, B. glumae has been identified as the major causal agent of bacterial grain rot (Nandakumar et al. 2005, 2009; Shahjahan et al. 2000). In the southern USA, yield losses caused by outbreaks of bacterial grain rot in rice fields in Louisiana were as much as $40 \%$ in 1995 and 1998; significant losses caused by this disease were also experienced in more recent years (Ham et al. 2011a, b; Nandakumar et al. 2009; Shahjahan et al. 2000; Zhou et al. 2011). Because the optimal temperature range for the growth of B. glumae is relatively high $\left(30-35{ }^{\circ} \mathrm{C}\right)$ (Kurita et al. 1964; Tsushima et al. 1986), this pathogen has emerged primarily in tropical and semi-tropical countries. Global warming may enable disease caused by B. glumae to reach destructive levels (Ham et al. 2011b); thus, this pathogen should be recognized as a potential threat to the world's rice production (Ham et al. 2010).

Seeds contaminated with B. glumae are sown and transplanted into fields and in some cases BSR appears 
(Azegami 2009; Azegami et al. 1988; Ham et al. 2011a; Tsushima 1996; Tsushima et al. 1989, 1991, 1996). Occasionally, the typical symptoms do not appear and plants with infected leaf sheaths seem to grow normally, making it difficult for farmers to identify the need to apply preventive agricultural chemicals. However, at heading, panicles are infected by vertical distribution from contaminated leaf sheaths. Thus, infected seeds cause both BSR and grain rot. The infection reduces yield owing to spikelet abortion and infected seeds also cause BSR and grain rot in the next generation (Ham et al. 2011b). Infection of rice seeds with B. glumae is associated with several endogenous and exogenous factors such as host susceptibility, inoculum density, humidity and temperature conditions (Azegami 2009; Goto 1983b; Mogi 1984a, b, c). Both high humidity and high temperature are conducive to infection of the seeds (Azegami 2009). In Japan, most rice seeds are sown in nursery boxes, and seedlings are moved to nursery beds before transplanting. Because nursery boxes are maintained under relatively high temperatures $\left(28-30{ }^{\circ} \mathrm{C}\right)$ to promote good germination, BSR tends to occur in nursery boxes if seeds are infected (Uematsu et al. 1976a, b). Seed treatment with oxolinic acid, a quinoline derivative, is a major means for the control of BSR in Japan (Hikichi 1993a, b; Hikichi et al. 1989). However, the occurrence of strains naturally resistant to oxolinic acid has been a serious limitation to this method of disease control (Hikichi et al. 2001; Maeda et al. 2004, 2007). Recently, plant rot after transplanting caused by $B$. glumae also has been reported in Japan (Hasegawa 2012), indicating that BSR has been more widespread than in the past.

Many studies have been performed to understand the genetic control of resistance to bacterial grain rot and several cultivars appear to be resistant to bacterial grain rot (Goto and Watanabe 1975; Groth et al. 2007; Imbe et al. 1986; Mogi and Tsushima 1985; Nandakumar et al. 2007a; Nandakumar and Rush 2008; Pinson et al. 2010; Prabhu and Bedendo 1988; Sayler et al. 2006; Sha et al. 2006; Takita et al. 1988; Wasano and Okuda 1994; Yasunaga et al. 2002). Using resistant cultivars, QTLs for resistance to bacterial grain rot have been reported (Mizobuchi et al. 2013; Pinson et al. 2010). In contrast, few reports about resistance to BSR have been published, because BSR resistance is a complex characteristic influenced by environmental factors (Azegami 2009; Goto 1982; Mogi 1984a, b, c). Although B. glumae causes both seedling rot and grain rot, no correlation between the resistance to each was observed (Goto 1983a). To date, no source of complete resistance has been identified (Goto 1983a; Sayler et al. 2006), although some cultivars show partial resistance (Goto et al. 1987; Hirashima and Wakimoto 1983; Sayler et al. 2006). However, the molecular mechanisms for resistance to BSR have not been analyzed and no breeding program for BSR resistance has been established.

In this study, we performed genetic analysis of resistance to BSR and successfully detected a QTL for resistance on chromosome 10 using chromosome segment substitution lines (CSSLs) developed from the cultivars Nona Bokra (resistant) and Koshihikari (susceptible). We also verified the effect of this QTL using an $\mathrm{F}_{5}$ population derived from a cross between a resistant CSSL and Koshihikari. We further delimited the candidate genomic region of the QTL by substitution mapping.

\section{Materials and methods}

Plant materials

To identify the chromosomal regions controlling resistance to BSR, 44 CSSLs, which were previously developed from a cross between Nona Bokra (resistant) and Koshihikari (susceptible) (Takai et al. 2007), were used. Nona Bokra, the donor parent, exhibits extremely late heading under natural field conditions in the summer in Tsukuba, Japan. Therefore, mature seeds of Nona Bokra were obtained using short-day equipment to promote heading.

On the basis of our initial results, we performed additional experiments with SL535, a resistant CSSL in which part of the short arm of chromosome 10 of Koshihikari was substituted with the corresponding segment of Nona Bokra. Forty-six $F_{2}$ plants were produced by crossing of SL535 with Koshihikari, and $46 \mathrm{~F}_{5}$ lines were developed by the single-seed-descent method and used for QTL analysis. For substitution mapping of the QTL for BSR, an additional $82 \mathrm{~F}_{2}$ seeds were sown in a growth chamber room. Out of the $128 \mathrm{~F}_{2}$ plants $(46+82)$, we selected 9 with recombination in the short arm of chromosome 10 and obtained $\mathrm{F}_{3}$ seeds. From each of the $\mathrm{F}_{3}$ lines, we selected an $\mathrm{F}_{3}$ plant that was homozygous for the recombinant chromosome and used the $\mathrm{F}_{4}$ lines derived from the $\mathrm{F}_{3}$ plants for substitution mapping.

\section{Assessment of BSR resistance}

The bacterial strain used in this study was B. glumae MAFF 301682 (MAFF: Culture collection of NIAS Genebank, National Institute of Agrobiological Sciences, formerly the culture collection of Ministry of Agriculture, Forestry and Fisheries, Japan), which was virulent on a large number of cultivars and maintained at the National Institute of Vegetable and Tea Science. Bacterial inocula were incubated on LB medium with $2 \%$ agar at $28{ }^{\circ} \mathrm{C}$ for 4 days and then adjusted to a concentration of $10^{8}$ per ml with sterilized, deionized water. Rice seeds were sterilized 
by soaking in chlorine bleach (available chlorine $2.5 \%$ ) for $30 \mathrm{~min}$ and rinsed carefully with sterilized water. The sterilized seeds were placed in a freshly prepared bacterial suspension and held under vacuum (0.2 MPa) for $3 \mathrm{~min}$. The inoculated seeds were dried overnight and then soaked in sterilized water for 2 days in a plant growth chamber at $27{ }^{\circ} \mathrm{C}$. The seeds were then sown in a sterilized soil (Bonsol No. 2, Sumitomo Kagaku Kougyo, Osaka, Japan) and incubated in a growth chamber at $27{ }^{\circ} \mathrm{C}$ with $80 \%$ humidity under a 14-h photoperiod with a photon flux intensity of $13.5 \mu \mathrm{mol} \mathrm{m} \mathrm{m}^{-2} \mathrm{~s}^{-1}$. Disease symptoms were scored 8 days after sowing on a scale of $1-3$, where $1=$ no symptoms, $2=$ sheaths with reddish-brown lesions (mild infection), and $3=$ necrotic seedlings or seeds with no germination (severe infection). The BSR ratio was calculated from these scores as:

BSR ratio $(\%)=\left(15-\left(N_{0}-N_{1} / 2\right)\right) \times 100 / 15$

where $N_{0}$ is the number of seedlings with score $1, N_{1}$ is the number of seedlings with score 2 , and 15 is the number of seeds per replication. There were four replications per inoculation. As a control, we germinated uninoculated seeds and confirmed that the average germination rate was $>90 \%$.

DNA extraction and simple sequence repeat (SSR) marker analysis

Total DNA was extracted from leaves by the CTAB method (Murray and Thompson 1980). To obtain SSR markers showing polymorphism between Nona Bokra and Koshihikari, SSR motifs were surveyed in the target chromosome regions (IRGSP 2005); the informative SSR markers identified by this screening were then used for genotyping of $\mathrm{F}_{5}$ plants. PCR amplifications were performed in 5- $\mu \mathrm{l}$ reaction mixtures containing $1.0 \mu \mathrm{l}(10 \mathrm{ng}) \mathrm{DNA}, 2.5 \mu \mathrm{l}$ of KAPA2G Fast ReadyMix $(2 \times)$ (Kapa Biosystems, Boston, MA, USA), $0.15 \mu 1$ of a $20-p M$ mixture of forward and reverse primers ( $20 \mathrm{pM}$ of each primer type), and $1.35 \mu \mathrm{l}$ $\mathrm{H}_{2} \mathrm{O}$. PCR consisted of an initial denaturation for $1 \mathrm{~min}$ at $95{ }^{\circ} \mathrm{C} ; 35$ cycles of $10 \mathrm{~s}$ at $95{ }^{\circ} \mathrm{C}, 10 \mathrm{~s}$ at $55^{\circ} \mathrm{C}$, and $1 \mathrm{~s}$ at $72{ }^{\circ} \mathrm{C}$; followed by a final extension for $30 \mathrm{~s}$ at $72{ }^{\circ} \mathrm{C}$. PCR products were separated by electrophoresis in $3 \%$ Agarose Type I gel (Sigma-Aldrich, St. Louis, MO, USA) at $150 \mathrm{~V}$ for $180 \mathrm{~min} .5 \mu \mathrm{l}$ of $50 \mathrm{ng} / \mu 1 \mathrm{DNA}$ was used in the SNP analysis. We used a 384-plex set of SNP markers selected from diverse accessions of cultivated Asian rice (Ebana et al. 2010). Genotyping was performed using the GoldenGate BeadArray technology platform (Illumina Inc., San Diego, CA, USA). These SNPs were detected using the Illumina Bead Station 500G system. All experimental procedures for the SNP typing followed the manufacturer's instructions.
Statistical and QTL analysis

Linkage mapping was performed using version 3.0 of MAPMAKER/EXP software (Lander et al. 1987), and the Kosambi map function was used to calculate genetic distances. QTL analyses were performed using composite interval mapping, as implemented by the Zmapqtl program (model 6) provided in version 2.5 of the QTL Cartographer software (Wang et al. 2005). Genome-wide threshold values $(\alpha=0.05)$ were used to detect putative QTLs on the basis of the results of 1,000 permutations. The significance of the difference in seedling rot was determined by Dunnett's test (JMP version 9.0 software, SAS Institute, Cary, NC, USA).

\section{Results}

Identification of a candidate chromosomal region for resistance to BSR in the CSSLs

The BSR ratios of Koshihikari and Nona Bokra were scored 8 days after sowing (Fig. 1). Almost all of the seeds of both cultivars germinated and their shoots emerged from the soil 3-4 days after sowing. The seedlings of Koshihikari showed typical symptoms $6-8$ days after sowing: some

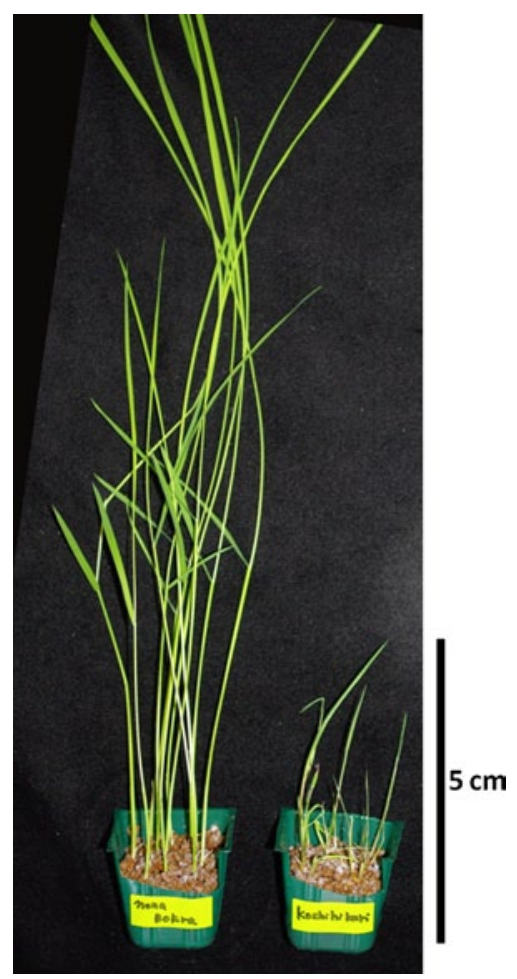

Fig. 1 Differences in resistance to bacterial seedling rot between Nona Bokra (left) and Koshihikari (right) 


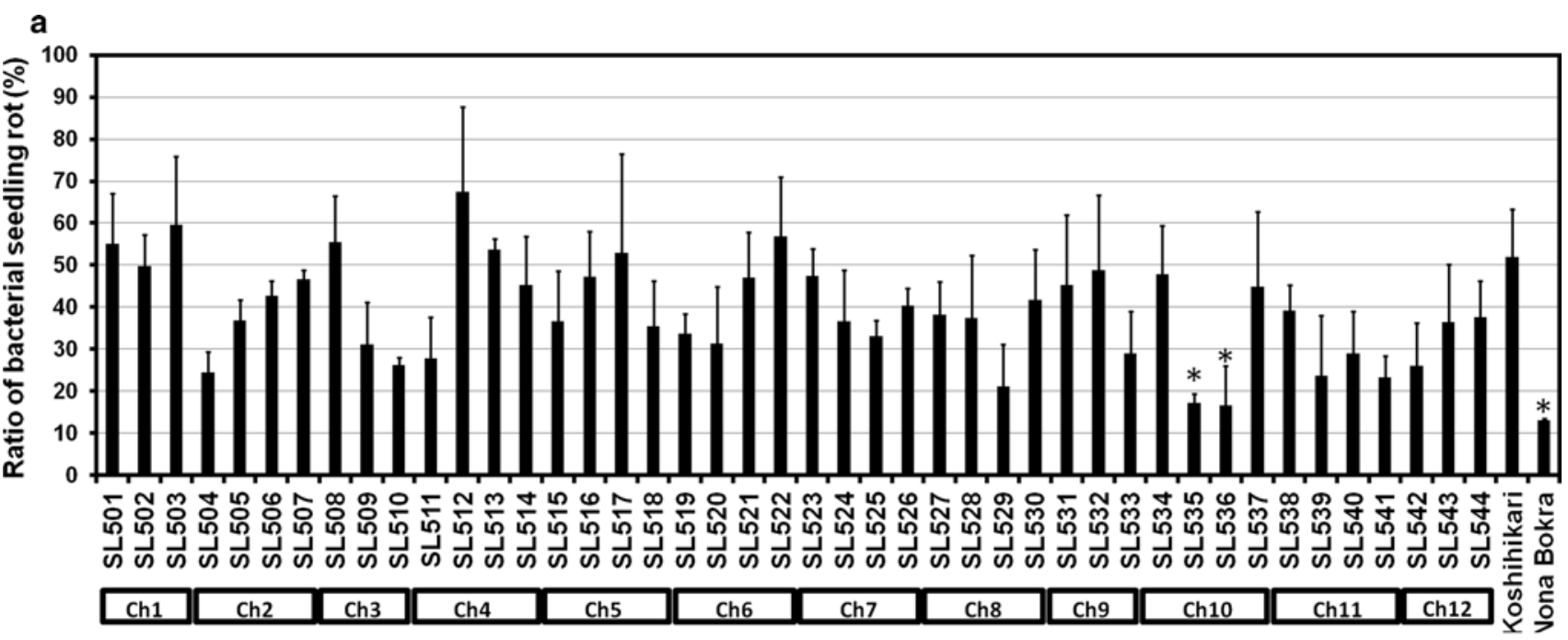

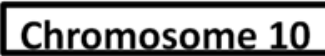

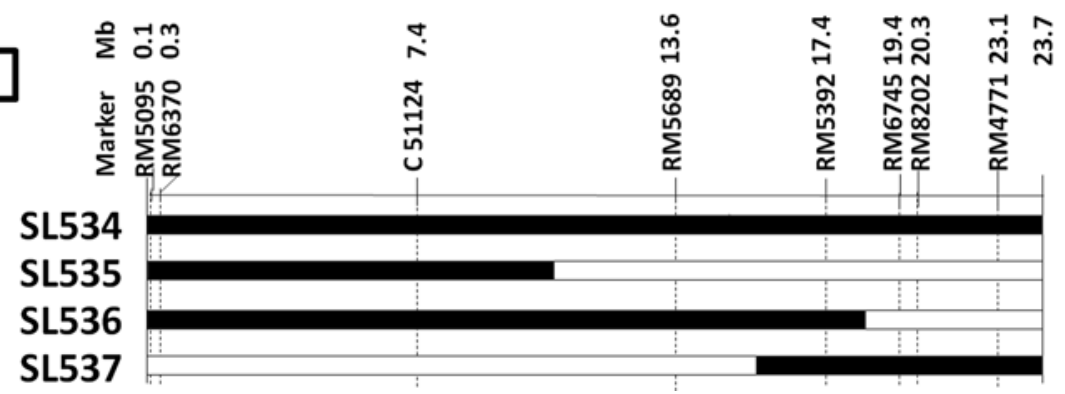

Fig. 2 a Bacterial seedling rot (BSR) ratios of Koshihikari, Nona Bokra, and 44 CSSLs derived from Koshihikari $\times$ Nona Bokra. The BSR ratio of each CSSL was scored 8 days after sowing of inoculated seeds. Chromosome numbers below the $x$ axis indicate the main Nona Bokra chromosome segment contained within each CSSL. Bars indicate means, and error bars indicate SD. *Significant difference from Koshihikari at the $5 \%$ level by Dunnett's test. b Graphical genotypes of chromosome 10 in CSSLs containing substitutions in this chromosome. SSR markers and physical distances based on RAPDB (IRGSP ver. 1) are indicated above the chromosome maps. White and black bars indicate regions from Koshihikari and Nona Bokra, respectively sheaths showed reddish-brown lesions and most of the others became necrotic. In contrast, most seedlings of Nona Bokra grew normally.

To identify the chromosomal segments involved in resistance to BSR, we determined the BSR ratios of the parents and the 44 CSSLs (Fig. 2a). The ratios of Koshihikari and Nona Bokra were 52.0 and $13.0 \%$, respectively. The BSR ratio varied widely among the CSSLs ranging from 16.6 to $67.4 \%$. The BSR ratios of 11 CSSLs (SL504, SL510, SL511, SL529, SL533, SL535, SL536, SL539, SL540, SL541, and SL542) were $<30.0 \%$; two of theseSL535 and SL536-had significantly lower ratios (17.1 and $16.6 \%$, respectively) than the Koshihikari control $(P<0.05$ by Dunnett's test). Both had segments of chromosome 10 derived from Nona Bokra (Fig. 2b). Therefore, we hypothesized that this region of chromosome 10 might be involved in the difference in the BSR ratio between Nona Bokra and Koshihikari.

\section{Detection of a QTL for resistance to BSR}

To confirm the presence of a putative QTL and to verify the effect of each allele, we developed advanced progeny from a cross between SL535 and Koshihikari. A QTL analysis using an $\mathrm{F}_{5}$ population derived from this cross revealed a wide range of variation in the BSR ratio (14.2 to $96.7 \%$ ) and detected one QTL between SSR markers RM474 and RM7361 on the short arm of chromosome 10 (Fig. 3a). This QTL accounted for $22 \%$ of the phenotypic variance in the $F_{5}$ plants, and the Nona Bokra allele decreased the BSR ratio by $21.7 \%$ (Fig. 3a). On the basis of the genotype at RM474, the SSR marker most closely linked to the QTL, we classified the $\mathrm{F}_{5}$ plants as homozygous for the Nona Bokra allele, homozygous for the Koshihikari allele, or heterozygous (Fig. 3b). $\mathrm{F}_{5}$ plants homozygous for the Koshihikari allele showed a high BSR mean ratio (81.4\%) ranging from 53.3 to $96.7 \%$. In contrast, the BSR mean ratio was 


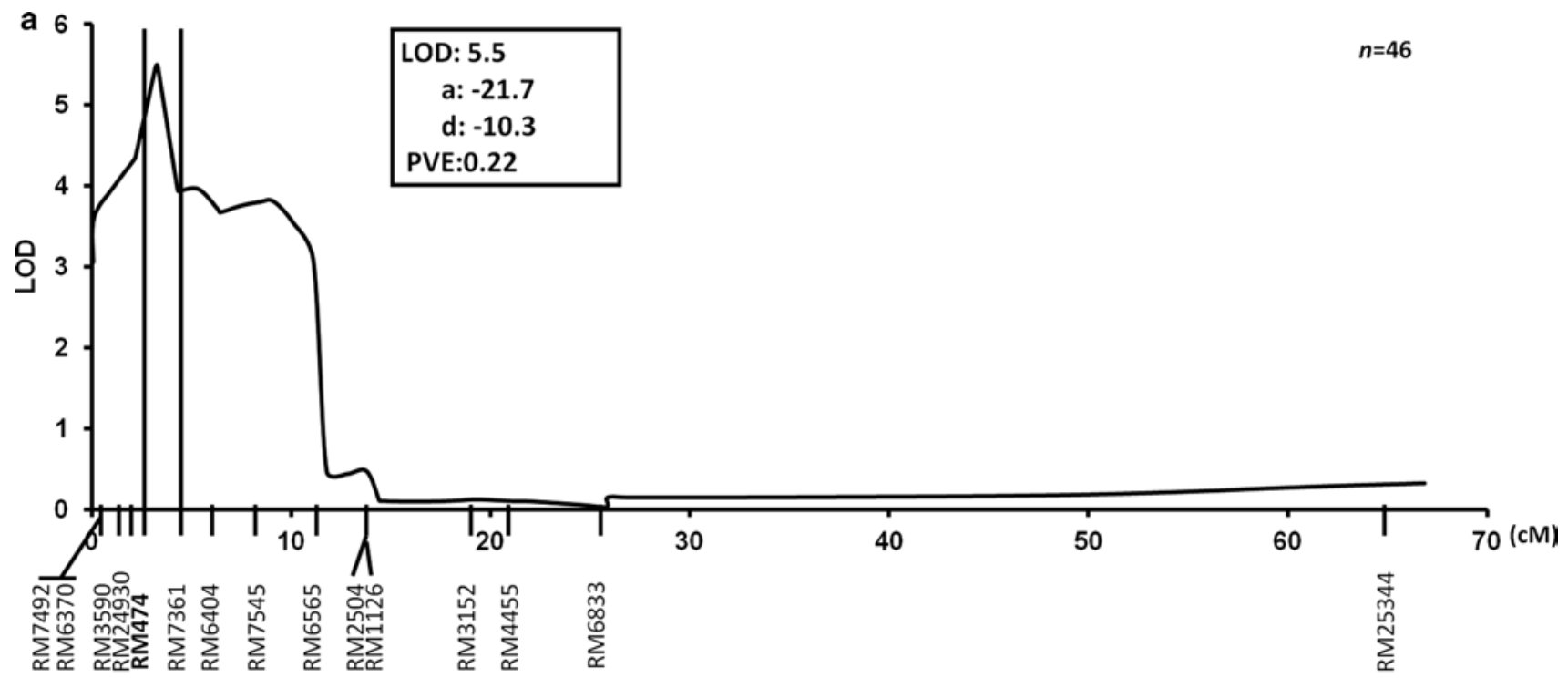

b

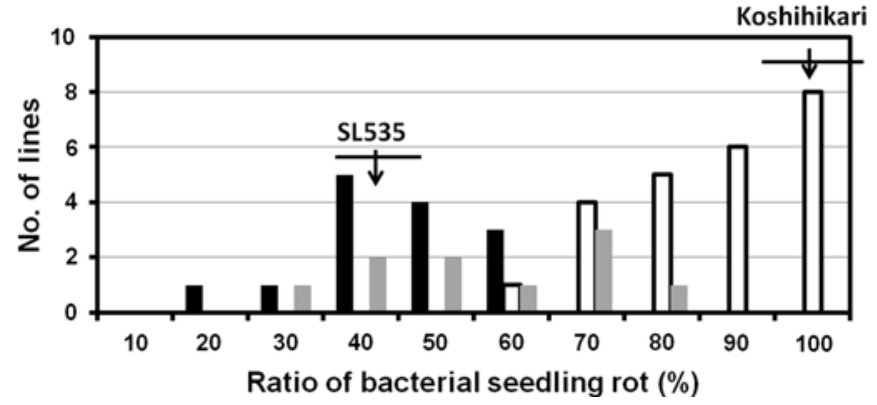

Fig. 3 Chromosomal location of a QTL for resistance to bacterial seedling rot (BSR) on the short arm of chromosome 10 and allelic differences for marker RM474. a The log-likelihood curve indicates a putative QTL position on chromosome 10 in an $\mathrm{F}_{5}$ population derived from Koshihikari $\times$ SL535. LOD logarithm of odds; $a$ additive effect of Nona Bokra allele, $d$ dominance effect of Nona Bokra allele, $P V E$ percentage of variance explained. b Frequency distribution of the BSR ratio in $F_{5}$ plants showing the three genotype classes of SSR

$40.7 \%$ ranging from 14.2 to $57.5 \%$ in plants homozygous for the Nona Bokra allele and $50.5 \%$ ranging from 24.2 to $73.3 \%$ in the heterozygous plants. The distribution of BSR ratios of plants homozygous for the Nona Bokra allele was shifted toward lower ratios than the distribution for heterozygotes. These results clearly confirmed the existence of a QTL on the short arm of chromosome 10 and that the Nona Bokra allele at the QTL decreased the BSR ratio.

Fine mapping of the QTL for resistance to BSR

To further delimit the candidate genomic region of the QTL for BSR, we genotyped $128 \mathrm{~F}_{2}$ plants derived from a cross between SL535 and Koshihikari and identified nine homozygous lines with recombination near RM474 (Fig. 4). We checked the genome of the lines and the parental cultivars (Koshihikari and Nona Bokra) by the SNP marker RM474, which was found to be linked to the QTL. Labels of $x$ axis indicate maximum BSR ratio in each bin. Genotypes of RM474 are represented as white bars (homozygous for Koshihikari allele), gray bars (heterozygous allele), and black bars (homozygous for Nona Bokra allele). The BSR ratios in the $\mathrm{F}_{5}$ population were determined 8 days after sowing. Arrows indicate the mean values for SL535 and Koshihikari; horizontal lines across the arrows indicate the standard deviations

analysis and found that the remaining genome in the lines was identical to that of Koshihikari except for the target region harboring qRBS1 (data not shown). Five lines (Nos. $1,2,3,4$, and 6) showed a low BSR ratio (32.2 to $51.7 \%$ ), whereas four (Nos. 5, 7, 8, and 9) showed a high BSR ratio (84.1 to $88.3 \%$; Fig. 4). These two phenotypic groups were associated with genotype classes that were homozygous for the Nona Bokra allele and the Koshihikari allele, respectively (Fig. 4). Together, the genotype and phenotype information clearly delimit the QTL for BSR ratio between SSR markers RM24930 and RM24944 (a 393-kb interval in the Nipponbare genome reference sequence) on chromosome 10 (Fig. 4). We have designated this QTL as $q R B S 1$ (quantitative trait locus for RESISTANCE TO BACTERIAL SEEDLING ROT 1), following the nomenclature recommended by McCouch and CGSNL (Committee on Gene Symbolization 2008). 


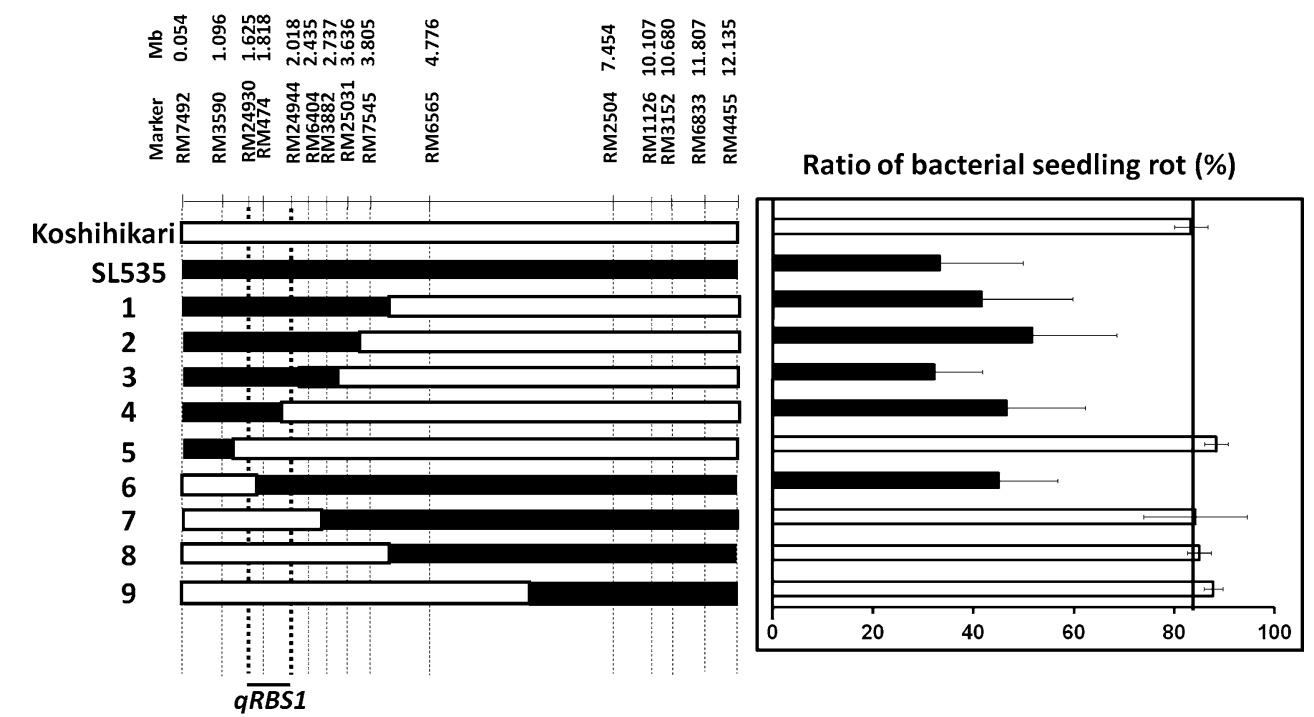

Fig. 4 Substitution mapping of a QTL controlling resistance to bacterial seedling rot (BSR) on the short arm of chromosome 10 in a set of nine homozygous $\mathrm{F}_{4}$ lines derived from Koshihikari $\times$ SL535. (left) Graphical genotypes. Black denotes regions homozygous for Nona Bokra marker alleles; white denotes regions homozygous for

\section{Discussion}

Identification of a major QTL for BSR in rice

Genetic analysis of BSR resistance is very difficult because the occurrence of BSR is highly affected by environmental conditions (Azegami 2009; Mogi 1984a, b, c). Therefore, only a few cultivars have been reported as partially resistant to BSR on the basis of disease lesion size and bacterial growth in plants (Goto 1983a; Hirashima and Wakimoto 1983; Sayler et al. 2006). Until now, no QTLs for BSR resistance have been reported.

Recent progress in genomics has enhanced understanding of the genetic basis of agronomic traits in rice, including those controlled by multiple loci (Yamamoto et al. 2009; Yano and Sasaki 1997). Advanced backcross progeny such as CSSLs can be useful for genetic analysis (Fukuoka et al. 2010b). Because each CSSL has only one or a few segment substitutions, it is possible to detect QTLs with minor effects generated by the substituted segments (Ebitani et al. 2005; Fukuoka et al. 2010a; Kubo et al. 2002; Marzougui et al. 2011; Takai et al. 2007). We were able to perform reliable assessment of BSR resistance using CSSLs, and we successfully identified a QTL for resistance to BSR, $q R B S 1$, located on the short arm of chromosome 10.

Nona Bokra showed a low BSR ratio (13.0 \%; Fig. 2a). Although SL535 and SL536, which have segments from chromosome 10 of Nona Bokra, showed lower BSR
Koshihikari marker alleles. The candidate QTL ( $q R B S 1)$ is indicated at the bottom. (right) The BSR ratio for each of the nine lines. Bars indicate means and error bars indicate SD. Vertical line indicates mean BSR score of Koshihikari. Black indicates a significant difference from Koshihikari at the $5 \%$ level by Dunnett's test

ratios than Koshihikari, SL534, which contained the same segment of chromosome 10, was not resistant (Fig. 2). Because SL534 also contained a very small segment of chromosome 6 (data not shown), this segment might influence the resistance to BSR. Conversely, several lines other than SL535 and SL536 also showed resistance to BSR, but did not contain chromosome 10 segments from Nona Bokra (Fig. 2a), indicating that $q R B S 1$ is only one QTL for BSR resistance segregating in this population. This may explain why SL535 is somewhat more susceptible to BSR than Nona Bokra, although it has a significantly lower BSR ratio than Koshihikari.

The conditions for assessment of resistance to BSR used in this experiment were severe. To characterize the effectiveness of $q R B S 1$ under agricultural conditions, we are currently comparing the resistance to BSR between a nearisogenic line (NIL) containing the Nona Bokra allele of $q R B S 1$ and Koshihikari, with or without agricultural chemicals and under mild disease conditions.

The candidate genomic region of $q R B S 1$ was mapped to the interval between RM24930 and RM24944 by substitution mapping (Fig. 4). According to the QTL Annotation Rice Online Database [Q-TARO, http://qtaro.abr. affrc.go.jp/; (Yonemaru et al. 2010)], no QTLs related to disease resistance have been reported in this region. Therefore, $q R B S 1$ appears to be a novel QTL. $q R B S 1$ was delimited to a $393-\mathrm{kb}$ region in the Nipponbare genome reference sequence. The Rice Annotation Project database [http://rapdb.dna.affrc.go.jp/ (Ohyanagi et al. 2006)] 
predicts 47 genes in the candidate region for $q R B S 1$. Among the predicted genes, there are three genes similar to NB-ARC domain containing protein and a gene similar to NBS-LRR class disease resistance protein. However, morphological and physiological functions of $q R B S 1$ are not yet known. Therefore, it is difficult to identify the actual candidate genes for $q R B S 1$ from among these many predicted genes. Further delimitation of the candidate genomic region will be necessary to identify the gene underlying the QTL.

\section{Progress toward improvement of resistance to BSR}

Recently, some bacteriophages were isolated to lyse some strains of B. glumae and suppress BSR and were reported to be more effective than pesticides (Adachi et al. 2012). However, in the actual agricultural phase, various bacteriophages lytic to a wide range of $B$. glumae are needed. Thus, it remains to be necessary to breed a resistant cultivar to BSR.

To utilize $q R B S 1$ for breeding, we are currently developing an NIL for $q R B S I$ in the Koshihikari genetic background. As noted above, some lines which do not have the Nona Bokra allele of $q R B S 1$ also showed resistance to BSR, suggesting that QTLs other than $q R B S 1$ are present in Nona Bokra. Thus, it may be necessary to combine qRBSI with those QTLs to achieve the level of BSR resistance seen in Nona Bokra. Because we used only one strain to assess the resistance of $q R B S 1$, it is still unknown whether $q R B S 1$ is race specific. To characterize the effectiveness of $q R B S 1$, we are planning to assess the resistance of $q R B S 1$ by several strains collected at a number of areas of Japan. Furthermore, to breed cultivars with stable resistance, it is necessary to search for resistant cultivars other than Nona Bokra to identify additional QTLs different from $q R B S 1$.

Seeds contaminated with $B$. glumae are sown and transplanted into fields, and in some cases BSR appears (Azegami 2009; Azegami et al. 1988; Ham et al. 2011a; Tsushima 1996; Tsushima et al. 1989, 1991, 1996). Occasionally, the typical symptoms do not appear and plants with leaf sheaths infected seem to grow normally. However, at heading, panicles are infected by vertical distribution from contaminated leaf sheaths. Plants, which are located near the diseased plants by primary infection, are also attacked by pathogen as secondary infection. The infection reduces yield owing to spikelet abortion, and infected seeds cause BSR and grain rot in the next generation (Ham et al. 2011b). BSR and bacterial grain rot have been widespread in Japan (Goto and Ohata 1956; Goto et al. 1987; Kurita and Tabei 1967; Uematsu et al. 1976a), East Asia (Azegami 2009; Chien and Chang 1987; Cottyn et al. 1996a, b; Jeong et al. 2003; Luo et al. 2007; Trung et al. 1993) and Latin America (Nandakumar et al. 2007b; Zeigler and Alvarez
1989). Therefore, it is necessary to breed cultivars, which are resistant to both BSR and bacterial grain rot.

Although B. glumae causes both seedling rot and grain rot, no correlation between the resistance to each was observed (Goto 1983a). We tested Nona Bokra and found that it was not resistant to grain rot (data not shown). In addition, the chromosomal position of $q R B S 1$ is different from those of QTLs reported to be associated with resistance to grain rot (Mizobuchi et al. 2013; Pinson et al. 2010). Therefore, the factors associated with resistance to seedling rot and grain rot appear to be different. Thus, it will be necessary to combine $q R B S 1$ and QTLs for resistance to bacterial grain rot to breed cultivars with stable resistance to both diseases.

Acknowledgments We thank the staff of the technical support section of the NIAS for their field management and experimental support. We thank Dr. K. Azegami (National Agriculture and Food Research Organization (NARO), National Institute of Vegetable and Tea Science) for kindly providing B. glumae MAFF 301682. We also thank the Rice Genome Resource Center (http://www.rgrc.dna.affrc. go.jp) for providing the CSSL seeds and Dr. K. Sugimoto of the NIAS for kindly providing $\mathrm{F}_{2}$ seeds of SL535 $\times$ Koshihikari. This work was supported by grants from the Ministry of Agriculture, Forestry and Fisheries of Japan (Project for Climate Change, Rice-2006).

Conflict of interest The authors declare that they have no conflict of interest.

Open Access This article is distributed under the terms of the Creative Commons Attribution License which permits any use, distribution, and reproduction in any medium, provided the original author(s) and the source are credited.

\section{References}

Adachi N, Tsukamoto S, Inoue Y, Azegami K (2012) Control of Bacterial Seedling Rot and Seedling Blight of Rice by Bacteriophage. Plant Dis 96:1033-1036

Azegami K (2009) Burkholderia glumae and Burkholderia plantarii, the pathogens of bacterial grain rot of rice and bacterial seedling blight of rice, respectively. MAFF Microorg Genet Resour Man 26:1-23

Azegami K, Nishiyama K, Tabei H (1988) Infection courts of rice seedlings with Pseudomonas plantarii and Pseudomonas glumae. Ann Phytopathol Soc Jpn 54:337-341

Chien CC, Chang YC (1987) The susceptibility of rice plants at different growth stages and 21 commercial rice varieties to Pseudomonas glumae. J Agric Res China 36:302-310

Cottyn B, Cerez MT, VanOutryve MF, Barroga J, Swings J, Mew TW (1996a) Bacterial diseases of rice. 1. Pathogenic bacteria associated with sheath rot complex and grain discoloration of rice in the Philippines. Plant Dis 80:429-437

Cottyn B, VanOutryve MF, Cerez MT, DeCleene M, Swings J, Mew TW (1996b) Bacterial diseases of rice. 2. Characterization of pathogenic bacteria associated with sheath rot complex and grain discoloration of rice in the Philippines. Plant Dis 80:438-445

Ebana K, Yonemaru J, Fukuoka S, Iwata H, Kanamori H, Namiki N, Nagasaki H, Yano M (2010) Genetic structure revealed by a whole-genome single-nucleotide polymorphism survey of diverse 
accessions of cultivated Asian rice (Oryza sativa L.). Breeding Sci 60:390-397

Ebitani T, Takeuchi Y, Nonoue Y, Yamamoto T, Takeuchi K, Yano M (2005) Construction and evaluation of chromosome segment substitution lines carrying overlapping chromosome segments of indica rice cultivar 'Kasalath' in a genetic background of japonica elite cultivar 'Koshihikari'. Breeding Sci 55:65-73

Fukuoka S, Ebana K, Yamamoto T, Yano M (2010a) Integration of Genomics into Rice Breeding. Rice 3:131-137

Fukuoka S, Nonoue Y, Yano M (2010b) Germplasm enhancement by developing advanced plant materials from diverse rice accessions. Breed Sci 60:509-517

Goto T (1982) Inoculation methods for resistance to bacterial seedling rot and grain rot in Burkholderia glumae. Ann Phytopathol Soc Jpn 48:373 (in Japanese)

Goto T (1983a) Resistance to Burkholderia glumae of lowland rice cultivars and promising lines in Japan. Ann Phytopathol Soc Jpn 49:410 (in Japanese)

Goto T (1983b) Rice bacterial grain rot, occurrence and research. (in Japanese). Shokubutsu Boeki 37:395-399

Goto K, Ohata K (1956) New bacterial diseases of rice (brown stripe and grain rot). Ann Phytophathol Soc Jpn 21:46-47

Goto T, Watanabe B (1975) Varietal resistance to bacterial grain rot of rice, caused by Pseudomonas glumae (in Japanese). Proc Assoc Pl Prot Kyushu 21:141-143

Goto T, Nishiyama K, Ohata K (1987) Bacteria causing grain rot of rice. Ann Phytopathol Soc Jpn 53:141-149

Groth DE, Linscombe SD, Sha X (2007) Registration of two diseaseresistant germplasm lines of rice. J Plant Regist 1:63-64

Ham J, Barphagha I, Karki H, Shrestha B, Melanson R, Chen R (2010) Identification of novel regulatory genes of Burkholderia glumae for virulence factors. Phytopathology 100:S47-S47

Ham J, Karki HS, Shrestha B, Barphagha IK, Melanson RA, Chen R, Groth DE, Sha X, Utomo H, Subudhi P, Rush MC (2011a) Molecular genetic and genomic studies on bacterial panicle blight of rice and its causative agent Burkholderia glumae. Phytopathology 101:S266-S266

Ham JH, Melanson RA, Rush MC (2011b) Burkholderia glumae: next major pathogen of rice? Mol Plant Pathol 12:329-339

Hasegawa M (2012) Chemical control of rice plant rot after transplanting caused by Burlholderia glumae. Jpn J Phytophatol 78:553

Hikichi Y (1993a) Antibacterial activity of oxolinic acid on Pseudomonas glumae. Ann Phytopathol Soc Jpn 59:369-374

Hikichi Y (1993b) Relationship between population dynamics of Pseudomonas glumae on rice plants and disease severity of bacterial grain rot of rice. J Pestic Sci 18:319-324

Hikichi Y, Noda C, Shimizu K (1989) Oxolic acid. Jpn Pestic Infect 55:21-23

Hikichi Y, Tsujiguchi K, Maeda Y, Okuno K (2001) Development of increased oxolinic acid-resistance in Burkholderia glumae. J Gen Plant Pathol 67:58-62

Hirashima K, Wakimoto T (1983) The differences of cultivars in resistance to bacterial seedling rot in rice. Ann Phytopathol Soc Jpn 49:411 (in Japanese)

Imbe T, Tsushima S, Nishiyama H (1986) Varietal resistance of rice to bacterial grain rot and screening method. Proc Assoc Pl Prot Kyushu 32:17-19

IRGSP (2005) The map-based sequence of the rice genome. Nature 436:793-800

Jeong Y, Kim J, Kim S, Kang Y, Nagamatsu T, Hwang I (2003) Toxoflavin produced by Burkholderia glumae causing rice grain rot is responsible for inducing bacterial wilt in many field crops. Plant Dis 87:890-895

Kubo T, Aida Y, Nakamura K, Tsunematsu H, Doi K, Yoshimura A (2002) Reciprocal chromosome segment substitution series derived from Japonica and Indica cross of rice (Oryza sativa L.). Breeding Sci 52:319-325

Kurita T, Tabei H (1967) On the pathogenic bacterium of bacterial grain rot of rice. Ann Phytopathol Soc Jpn 33:111

Kurita T, Tabei H, Sato T (1964) A few studies on factors associated with infection of bacterial grain rot of rice. Ann Phytopathol Soc Jpn 29:60

Lander E, Green P, Abrahamson J, Barlow A, Daley M, Lincoln S, Newburg L (1987) MAPMAKER: an interactive computer package for constructing primary genetic linkage maps of experimental and natural populations. Genomics 1:174-181

Luo J, Xie G, Li B, Lihui X (2007) First report of Burkholderia glumae isolated from symptomless rice seeds in china. Plant Dis 91:1363-1364

Maeda Y, Kiba A, Ohnishi K, Hikichi Y (2004) Implications of amino acid substitutions in GyrA at position 83 in terms of oxolinic acid resistance in field isolates of Burkholderia glumae, a causal agent of bacterial seedling rot and grain rot of rice. Appl Environ Microb 70:5613-5620

Maeda Y, Kiba A, Ohnishi K, Hikichi Y (2007) Amino acid substitutions in GyrA of Burkholderia glumae are implicated in not only oxolinic acid resistance but also fitness on rice plants. Appl Environ Microb 73:1114-1119

Marzougui S, Sugimoto K, Yamanouchi U, Shimono M, Hoshino T, Hori K, Kobayashi M, Ishiyama K, Yano M (2011) Mapping and characterization of seed dormancy QTLs using chromosome segment substitution lines in rice. Theor Appl Genet 124:893-902

McCouch S, CGSNL (Committee on Gene Symbolization NaL, Rice Genetics Cooperative) (2008) Gene nomenclature system for rice. Rice 1:72-84

Mizobuchi R, Sato H, Fukuoka S, Tanabata T, Tsushima S, Imbe T, Yano M (2013) Mapping a quantitative trait locus for resistance to bacterial grain rot in rice. Rice 6:13

Mogi S (1984a) Occurrence and control of Burkholderia glumae in rice (1). Agric Hortic 59:679-682 (in Japanese)

Mogi S (1984b) Occurrence and control of Burkholderia glumae in rice (2). (in Japanese). Agric Hortic 59:782-788

Mogi S (1984c) Occurrence and control of Burkholderia glumae in rice (3). Agric Hortic 59:899-903 (in Japanese)

Mogi S, Tsushima S (1985) Varietal resistance to bacterial grain rot in rice, caused by Pseudomonas glumae. Kyushu Agric Res 47:103

Murray MG, Thompson WF (1980) Rapid isolation of high molecular weight plant DNA. Nucleic Acids Res 8:4321-4325

Nandakumar R, Rush MC (2008) Analysis of gene expression in Jupiter rice showing partial resistance to rice panicle blight caused by Burkholderia glumae. Phytopathology 98:S112

Nandakumar R, Rush M, Shahjahan A, O'Reilly K, Groth D (2005) Bacterial panicle blight of rice in the southern United States caused by Burkholderia glumae and B. gladioli. Phytopathology 95:S73

Nandakumar R, Bollich P, Groth D, Rush MC (2007a) Confirmation of the partial resistance of Jupiter rice to bacterial panicle blight caused by Burkholderia glumae through reduced disease and yield loss in inoculated field tests. Phytopathology 97: S82-S83

Nandakumar R, Rush MC, Correa F (2007b) Association of Burkholderia glumae and B. gladioli with panicle blight symptoms on rice in Panama. Plant Dis 91:767

Nandakumar R, Shahjahan AKM, Yuan XL, Dickstein ER, Groth DE, Clark CA, Cartwright RD, Rush MC (2009) Burkholderia glumae and B. gladioli cause bacterial panicle blight in rice in the southern United States. Plant Dis 93:896-905

Ohyanagi H, Tanaka T, Sakai H, Shigemoto Y, Yamaguchi K, Habara T, Fujii Y, Antonio BA, Nagamura Y, Imanishi T, Ikeo K, Itoh T, Gojobori T, Sasaki T (2006) The Rice Annotation Project Database (RAP-DB): hub for Oryza sativa ssp. japonica genome information. Nucleic Acids Res 34:D741-D744 
Pinson SRM, Shahjahan AKM, Rush MC, Groth DE (2010) Bacterial panicle blight resistance QTLs in rice and their association with other disease resistance loci and heading date. Crop Sci 50:1287-1297

Prabhu AS, Bedendo IP (1988) Glume blight of rice in Brazil: etiology, varietal reaction and loss estimates. Trop Pest Manag 34:85-88

Sayler RJ, Cartwright RD, Yang YN (2006) Genetic characterization and real-time PCR detection of Burkholderia glumae, a newly emerging bacterial pathogen of rice in the United States. Plant Dis 90:603-610

Sha X, Linscombe SD, Groth DE, Bond JA, White LM, Chu QR, Utomo HS, Dunand RT (2006) Registration of 'Jupiter' rice. Crop Sci 46:1811-1812

Shahjahan AKM, Rush MC, Groth D, Clark CA (2000) Panicle blight. Rice J 15:26-29

Takai T, Nonoue Y, Yamamoto SI, Yamanouchi U, Matsubara K, Liang ZW, Lin HX, Ono N, Uga Y, Yano M (2007) Development of chromosome segment substitution lines derived from backcross between indica donor rice cultivar 'Nona bokra' and japonica recipient cultivar 'Koshihikari'. Breeding Sci 57: 257-261

Takita T, Imbe T, Nishiyama H, Tsushima S (1988) Resistance to rice bacterial grain rot in indica and upland rice. Kyushu Agric Res 50:28

Trung HM, Van NV, Vien NV, Lam DT, Lien M (1993) Occurrence of rice grain rot disease in Vietnam. Int Rice Res Notes 18:30

Tsushima S (1996) Epidemiology of bacterial grain rot of rice caused by Pseudomonas glumae. JARQ 30:85-89

Tsushima S, Mogi S, Saito H (1986) Effect of temperature on the growth of Pseudomonas glumae and the development of rice bacterial grain rot. Proc Assoc Pl Prot Kyushu 32:14-16

Tsushima S, Mogi S, Naito H, Saito H (1989) Existence of Pseudomonas glumae on the rice seeds and development of the simple method for detecting P. glumae from the rice seeds. Bull Kyushu Natl Agric Exp Stn 25:261-270
Tsushima S, Mogi S, Naito H, Saito H (1991) Populations of Pseudomonas glumae on rice plants. Ann Phytopathol Soc Jpn 57:145-152

Tsushima S, Naito H, Koitabashi M (1996) Population dynamics of Pseudomonas glumae, the causal agent of bacterial grain rot of rice, on leaf sheaths of rice plants in relation to disease development in the field. Ann Phytopathol Soc Jpn 62:108-113

Uematsu T, Yoshimura D, Nishiyama K, Ibaragi T, Fujii H (1976a) Pathogenic bacterium causing seedling rot of rice. Ann Phytopathol Soc Jpn 1976:464-471

Uematsu T, Yoshimura D, Nishiyama K, Ibaraki T, Fujii H (1976b) Occurrence of bacterial seedling rot in nursery flat, caused by grain rot bacterium Pseudomonas glumae. Ann Phytopathol Soc Jpn 42:310-312

Wang S, Basten CJ, Zeng ZB (2005) Windows QTL Cartigrapher 2.5. Department of Statistics, North Carolina State University, Raleigh. http://statgen.ncsu.edu/qtlcart/WQTLCart.htm

Wasano K, Okuda S (1994) Evaluation of resistance of rice cultivars to bacterial grain rot by the syringe inoculation method. Breeding Sci 44:1-6

Yamamoto T, Yonemaru J, Yano M (2009) Towards the understanding of complex traits in rice: substantially or superficially? DNA Res $16: 141-154$

Yano M, Sasaki T (1997) Genetic and molecular dissection of quantitative traits in rice. Plant Mol Biol 35:145-153

Yasunaga T, Wada T, Oosata KF, Hamachi Y (2002) Varietal differences in occurrence of bacterial grain rot in rice cultivars with high palatability. Crop Sci Soc Jpn 68:12-14

Yonemaru J, Yamamoto T, Fukuoka S, Uga Y, Hori K, Yano M (2010) Q-TARO: QTL Annotation Rice Online Database. Rice 3:194-203

Zeigler RS, Alvarez E (1989) Grain discoloration of rice caused by Pseudomonas glumae in Latin America. Plant Dis 73:368

Zhou XG, McClung AM, Way MO, Jo Y, Tabien RE, Wilson LT (2011) Severe outbreak of bacterial panicle blight across Texas Rice Belt in 2010. Phytopathology 101:S205 